\title{
Design and development of an instrument to measure overall lifestyle habits for epidemiological research: the Mediterranean Lifestyle (MEDLIFE) index
}

\author{
Mercedes Sotos-Prieto ${ }^{1,2, *}$, Belén Moreno-Franco ${ }^{3}$, Jose M Ordovás ${ }^{1,4}$, Montse León ${ }^{5}$, \\ Jose A Casasnovas ${ }^{5}$ and Jose L Peñalvo ${ }^{1}$ \\ 'Department of Epidemiology, Atherothrombosis, and Imaging, Centro Nacional de Investigaciones \\ Cardiovasculares (CNIC), 28029 Madrid, Spain: ${ }^{2}$ International SHE Foundation, 08037 Barcelona, Spain: \\ ${ }^{3}$ Department of Medicine, Psychiatry and Dermatology, University of Zaragoza, Zaragoza, Spain: ${ }^{4}$ Nutrition and \\ Genomics Laboratory, Jean Mayer-USDA Human Nutrition Research Center on Aging at Tufts University, Boston, \\ MA, USA: ${ }^{5}$ Cardiovascular Research Unit, Instituto Aragonés de Ciencias de la Salud (I+CS), Zaragoza, Spain
}

Submitted 8 October 2013: Final revision received 14 May 2014: Accepted 6 June 2014: First published online 15 July 2014

\begin{abstract}
Objective: To design and develop a questionnaire that can account for an individual's adherence to a Mediterranean lifestyle including the assessment of diet and physical activity patterns, as well as social interaction.

Design: The Mediterranean Lifestyle (MEDLIFE) index was created based on the current Spanish Mediterranean food guide pyramid. MEDLIFE is a twenty-eightitem derived index consisting of questions about food consumption (fifteen items), traditional Mediterranean dietary habits (seven items) and physical activity, rest and social interaction habits (six items). Linear regression models and Spearman rank correlation were fitted to assess content validity and internal consistency. Setting: A subset of participants in the Aragon Workers' Health Study cohort (Zaragoza, Spain) provided the data for development of MEDLIFE.

Subjects: Participants ( $n$ 988) of the Aragon Workers' Health Study cohort in Spain. Results: Mean MEDLIFE score was 11.3 (SD 2.6; range: 0-28), and the quintile distribution of MEDLIFE score showed a significant association with each of the individual items as well as with specific nutrients and lifestyle indicators (intra-validity). We also quantified MEDLIFE correspondence with previously reported diet quality indices and found significant correlations ( $\rho$ range: $0 \cdot 44-0.53$; $P<0 \cdot 001)$ for the Alternate Healthy Eating Index, the Alternate Mediterranean Diet Index and Mediterranean Diet Adherence Screener.

Conclusions: MEDLIFE is the first index to include an overall assessment of lifestyle habits. It is expected to be a more holistic tool to measure adherence to the Mediterranean lifestyle in epidemiological studies.
\end{abstract}

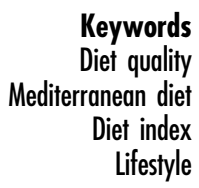

The Mediterranean diet has repeatedly been associated with reduced cardiovascular outcomes ${ }^{(1-4)}$. How to measure an individual's or a population's adherence to a specific healthy diet has been always a challenge, and several indices have been proposed to assess the overall quality of diet. The Alternate Healthy Eating Index $(\mathrm{AHEI})^{(3)}$ was developed based on dietary guidelines and the food guide pyramid proposed by the US Department of Agriculture ${ }^{(5)}$ and emphasizes the consumption of plant foods and unsaturated oils. The Alternate Mediterranean Diet Index (aMED) ${ }^{(1)}$ was adapted from the original Greek Mediterranean Diet Scale ${ }^{(6)}$ for the US population, by introducing some modifications such as eliminating the dairy group, separating nuts and fruits into two groups, and assigning a score to a moderate alcohol intake. These modifications were derived from results from observational studies showing associations between certain dietary patterns and lower rates of cardiovascular risk. More recently, a 14-point Mediterranean Diet Adherence Screener (MEDAS) ${ }^{(7)}$ questionnaire was validated and developed within the PREDIMED study $^{(2)}$ and included two additional questions on dietary habits considered characteristic of the Mediterranean diet (choice of olive oil as the main fat for cooking and choice of white over red meat) in addition to assessing consumption of specific food groups. 
Diet is a major component of an individual's lifestyle. Single nutrients, food groups or even dietary patterns (e.g. AHEI, aMED and other dietary indices) can be used as an indicator of overall lifestyle, but it now seems obvious that we will miss fundamental information if no other behaviours are taken into account. Associations between diet and different cardiovascular outcomes could be strengthened by accounting for an in-depth understanding of lifestyle covariates ${ }^{(8,9)}$. Diet patterns are closely related to eating habits, and also with cultural and psychological aspects of lifestyle that must be addressed. Psychosocial factors such as job strain, stress, anxiety, resting patterns, and family and community support are directly linked with lifestyle and greatly influence cardiovascular health. Bhupathiraju et $a l .{ }^{(9)}$ evaluated the American Heart Association diet approach and other lifestyle recommendations (BMI and physical activity) in relation to CVD risk factors in a sample of Boston Puerto Ricans. However, no other components have been considered in the lifestyle index and so far existing indices do not account for other components beyond diet. Evidence from a number of studies demonstrates that, as part of the physical lifestyle environment, physical activity, sociability and adequate rest seem to be related with CVD development ${ }^{(10-13)}$. The assessment of these factors and conditions is challenging, but fortunately the Mediterranean lifestyle includes a series of very well-characterized behaviours (physical activity, sociability, siesta, etc.) that can serve as a proxy for an overall assessment of lifestyle beyond diet ${ }^{(14)}$.

In fact, the new Mediterranean Diet Pyramid recently developed in Spain by the Mediterranean Diet Foundation includes guidelines for cultural, social and gastronomic characteristics that define a Mediterranean lifestyle ${ }^{(14)}$. This Mediterranean pyramid is supported by a number of international institutions and societies, and experts from various disciplines, and has been translated into multiple languages ${ }^{(14,15)}$. Therefore, based on these principles and in view of the lack of lifestyle indices, our objective was to describe the design and development of a Mediterranean Lifestyle (MEDLIFE) index based on the Mediterranean Diet Pyramid to quantify the adherence to a healthy (Mediterranean) lifestyle that includes, besides food consumption, other behavioural components such as physical activity, rest and social interactions. A secondary objective was to conduct a preliminary internal validation.

\section{Methods}

\section{Study participants}

The Aragon Workers' Health Study (AWHS) is a cohort study based on the annual health examinations of the workers of the General Motors Spain automobile assembly plant located in Figueruelas (Zaragoza, Spain). The overall aim of the study was to characterize the factors associated with metabolic abnormalities and subclinical atherosclerosis in a middle-aged (40-55 years old) population ( $n$ 3109) free of clinical CVD, whose methodology has been previously described ${ }^{(16)}$. Baseline measurements included evaluation of subclinical atherosclerosis by imaging techniques and additional questionnaires on cardiovascular and lifestyle factors ${ }^{(16)}$. Our investigation was conducted in the first 1100 participants who completed the questionnaire on food consumption frequency (FFQ). From this sample of participants, we excluded those who did not respond to the FFQ or who reported an implausible dietary intake $(<3347 \mathrm{~kJ}(<800 \mathrm{kcal})$ or $>17573 \mathrm{~kJ}$ ( $4200 \mathrm{kcal})$ ). The original data collection instrument is included as supplementary material. The final sample consisted of 988 individuals. The AWHS was approved by the Central Institutional Review Board of Aragón (CEICA). All study participants provided written informed consent.

\section{Dietary assessment and calculation of diet quality indices}

Dietary intake and habits were assessed using a semiquantitative FFQ previously validated for the Spanish population $^{(17)}$, capturing long-term intake during the preceding year, taking into account seasonal variations and differences between weekday and weekend patterns. The questionnaire is based on 136 food items, including specific questions about consumption of supplements and information on adherence to restrictive diets. For each food included in the questionnaire, serving size was specified with the choice between nine frequencies of consumption from 'never or almost never' to 'more than six times a day'.

Diet quality indices (AHEI, aMED and the 14-point MEDAS) were calculated by using the information derived from the FFQ described above. In the absence of exact information on specific items, modifications from the published criteria were introduced (see online supplementary material). The AHEI, adapted from the original $\mathrm{HEI}^{(5)}$, provides quantitative scoring for nine components $^{(3)}$. Its scoring criteria are described in Supplemental Table 1. All items, except multivitamin use, of the AHEI each contribute $0-10$ points to the total score. The total AHEI ranges from 2.5 (worst) to 87.5 (best). The aMED ${ }^{(1)}$ was adapted from the former Mediterranean Diet Scale by Trichopoulou and co-workers ${ }^{(6)}$. Evaluated items include nine components. Median intakes for each item are considered as cut-offs for assigning 1 point (intake greater than the median) or 0 points (intake less than the median), with the exception of red and processed meat consumption and alcohol intake (Supplemental Table 2), with final score ranging from 0 (worst) to 9 (best). The MEDAS (a self-questionnaire used in the PREDIMED study) consists of twelve questions on the frequency of consumption of specific foods and two additional questions on dietary habits considered characteristic of a Mediterranean diet. Each question is scored 0 or 1 (Supplemental Table 3). The final MEDAS ranges from 0 (worst) to 14 (best). 


\section{Assessment of non-dietary variables}

Physical activity was assessed using the Spanish validated version $^{(18)}$ of the Nurses' Health Study (NHS) and Health Professionals Follow-up Study (HPFS) physical activity questionnaires $^{(19,20)}$. The questionnaire also includes questions about habits and lifestyle such as time spent sitting $(\mathrm{h} / \mathrm{d})$, watching television or video $(\mathrm{h} / \mathrm{d})$, in front of a computer $(h / d)$, sleeping $(h / d)$ or socializing with friends $(h / d)$, differentiating between a typical weekday and a typical day weekend. Participants also completed an additional questionnaire on sociodemographic characteristics including education level, years of employment at the factory, shift and type of work performed, marital status, number of children and number of people who form their family unit.

\section{Development of the Mediterranean Lifestyle (MEDLIFE) index}

The MEDLIFE index was created based on following the principles of the Mediterranean Diet Pyramid ${ }^{(14,15)}$ recently proposed by the Spanish Mediterranean Diet Foundation. A total of twenty-eight items were derived interpreting the pyramid and divided into three blocks. The first block contained items gathering food consumption frequency (fifteen items). The second block included items on Mediterranean dietary habits (seven items) and the third block, physical activity, rest, social habits and conviviality (six items). Each item scored 0 or 1 . For each of the twenty-eight items, 1 point was given if the answer met the following conditions: (i) pastries, $\leq 2$ servings/week; (ii) red meat, $<2$ servings/week; (iii) processed meat, $\leq 1$ servings/week; (iv) eggs, 2-4 servings/week; (v) legumes, $\geq 2$ servings/ week; (vi) white meat, 2 servings/week; (vii) fish or seafood, $\geq 2$ servings/week; (viii) potatoes, $\leq 3$ servings/week; (ix) low-fat dairy products, 2 servings/d; (x) nuts including olives, 1-2 servings/d; (xi) herbs, spices and garnish (including onion, garlic or other herbs such as parsley, oregano), $\geq 1$ serving/d; (xii) fruit including fresh juice, 3-6 servings/d; (xiii) vegetables (except potatoes), $\geq 2$ servings/ $\mathrm{d}$; (xiv) olive oil consumption, $\geq 3 \mathrm{tbsp} / \mathrm{d}$ ( $1 \mathrm{tbsp}=13.5 \mathrm{~g}$ ); (xv) cereals, 3-6 servings/d; (xvi) 6-8 glasses of water/d or $\geq 3$ servings of infusions/week; (xvii) wine (red or white), 1-2 servings/d; (xviii) preference for whole grain products (or $>25$ g fibre/d); (xix) snacks, $\leq 2$ servings/week. Three additional questions queried traditional Mediterranean habits: ( $\mathrm{xx}$ ) 'Do you limit salt addition during meals?'; (xxi) 'Do you limit nibbling between meals?'; (xxii) 'Do you limit sugar addition in beverages (including sugar-sweetened beverages)?' And six additional questions asked about physical activity, rest, social habits and conviviality: (xxiii) physical activity (moderate physical activity $\geq 150 \mathrm{~min} /$ week, 500-1000 MET/min per week or $30 \mathrm{~min}$ brisk walking, where $\mathrm{MET}=$ metabolic equivalent of task) ${ }^{(21,22)}$; (xxiv) nap during weekend; (xxv) 6-8h sleep/d during weekdays $^{(12,13,23)}$; (xxvi) watching television for $<1 \mathrm{~h} / \mathrm{d}$ during weekdays; (xxvii) $\geq 2 \mathrm{~h}$ during weekend dedicated to going out with friends; (xxviii) doing collective sports (cycling, jogging, soccer, etc.) for $\geq 2 \mathrm{~h} /$ week. The final MEDLIFE index ranged from 0 (worst) to 28 (best; Table 1).

By design (following the principles of the Mediterranean Diet Pyramid: a lifestyle for today) and considering the main goal of utility of the index (being used as an independent short screener tool in epidemiological and clinical studies), each question is weighted equally and the scale of scoring this index is categorical. This will simplify the administration of the screener in future studies.

\section{Statistical analysis/data analysis}

We calculated Spearman rank correlation coefficients between the calculated diet quality indices (AHEI, aMED and MEDAS) and the MEDLIFE index. The $\kappa$ statistic was used to evaluate the agreement between quintile distributions of the different indices. To assess content validity and internal consistency, linear regression models were fitted to determine $\beta$ coefficients for quantifying the association between each MEDLIFE item and nutrient intakes (as continuous variables) derived from the FFQ. The regression models were adjusted for age (continuous), gender (male or female) and total energy intake (continuous). Adjusted means of each MEDLIFE item as well as other nutrient intakes according to quintile distribution of the MEDLIFE index were calculated. When the dependent variable was categorical, logistic regression was used. The $P$ trend was tested across quintiles of MEDLIFE index distribution. Further statistical analyses conducted to evaluate internal consistency included Spearman rank correlations to examine associations between individual component scores and the total MEDLIFE index and Cronbach's $\alpha$ as a further estimate of internal consistency and reliability. $P<0.05$ was considered as statistically significant and all tests were two-tailed. Statistical analyses were conducted using the statistical software package STATA version $12 \cdot 0$.

\section{Results and discussion}

\section{The overall MEDLIFE index development}

The MEDLIFE index includes twenty-eight items divided into three different blocks, i.e. food consumption, dietary patterns and physical activity, rest, social habits and conviviality. Table 1 shows a description of each of the items and the scoring criteria. For each item we present the percentage of participants receiving the maximum score (1 point). In the food consumption block, only $6 \cdot 1 \%$ met 1 -point criteria for processed meat ( $\leq 1$ serving/week) and white meat (2 servings/week). Less than $50 \%$ scored 1 point for fruit (18.0\%, 3-6 servings/d), nuts (19.7\%, 1-2 servings/d), olive oil ( $28 \cdot 1 \%, \geq 3$ servings/d) and legumes $(31 \cdot 1 \%, \geq 2$ servings/week) consumption. However, $90.2 \%$ and $80.0 \%$ consumed fish/seafood and vegetables in $\geq 2$ servings/week, respectively. As for food habits, only $15.7 \%$ consumed 1-2 servings of wine daily and $69 \cdot 1 \%$ 


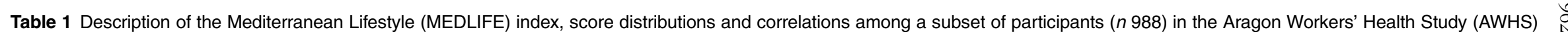
cohort (Zaragoza, Spain)

\begin{tabular}{|c|c|c|c|c|c|}
\hline Food group & Foods included & Criteria for 1 point* & $n$ & $\%$ & $\begin{array}{l}\text { Spearman } \\
\text { rank } \rho\end{array}$ \\
\hline \multicolumn{6}{|c|}{ Block 1: Mediterranean food consumption } \\
\hline 1. Sweets & $\begin{array}{l}\text { Candy ( } 1 \text { serving }=1 \text { unit or } 50 \mathrm{~g}) \text {, chocolates }(1 \text { serving }=30 \mathrm{~g}) \text {, } \\
\text { biscuits }(1 \text { serving }=4-6 \text { units), turron }(1 \text { serving }=40 \mathrm{~g})\end{array}$ & $\leq 2$ servings/week & 123 & $12 \cdot 5$ & 0.21 \\
\hline 2. Red meat & Beef, pork, lamb (1 serving $=100-150 \mathrm{~g})$ & $<2$ servings/week & 244 & 24.7 & 0.20 \\
\hline 3. Processed meat & $\begin{array}{l}\text { Ham }(1 \text { serving }=1 \text { slice or } 30 \mathrm{~g}) \text {, sausage, soft spicy sausage, bacon } \\
(1 \text { serving }=50 \mathrm{~g}) \text {, hamburger }(1 \text { serving }=1 \text { unit), liver } \\
(1 \text { serving }=100-150 \mathrm{~g}) \text {, pâté }(1 \text { serving }=25 \mathrm{~g})\end{array}$ & $\leq 1$ serving/week & 60 & $6 \cdot 1$ & 0.18 \\
\hline 4. Eggs & Eggs ( 1 egg) & 2-4 servings/week & 649 & $65 \cdot 7$ & 0.16 \\
\hline 5. Legumes & Lentils, beans, peas, chickpeas ( 1 serving $=1$ plate or $150 \mathrm{~g}$ ) & $\geq 2$ servings/week & 307 & $31 \cdot 1$ & 0.21 \\
\hline 6. White meat & Poultry and rabbit $(1$ serving $=100-150 \mathrm{~g})$ & 2 servings/week & 60 & $6 \cdot 1$ & 0.13 \\
\hline 7. Fish/seafood & $\begin{array}{l}\text { White } / \text { oily fish }(1 \text { serving }=100-150 \mathrm{~g}) \text {, canned fish }(1 \text { serving }=1 \text { can } \\
\text { or } 50 \mathrm{~g}) \text {, seafood }(1 \text { serving }=200 \mathrm{~g})\end{array}$ & $\geq 2$ servings/week & 891 & $90 \cdot 2$ & 0.22 \\
\hline 8. Potatoes & Roast/boiled potatoes, French fries $(1$ serving $=150-200 \mathrm{~g}$ ) & $\leq 3$ servings/week & 231 & 23.4 & 0.10 \\
\hline 9. Low-fat dairy products & Skimmed dairy milk ( 1 serving $=1$ cup or $200 \mathrm{ml}$ ), soft cheese & $\overline{2}$ servings/d & 16 & 1.6 & 0.11 \\
\hline 10. Nuts and olives & $\begin{array}{l}\text { Walnuts, almonds, hazelnuts ( } 1 \text { serving }=1 \text { handful or } 30 \mathrm{~g} \text { ), olives } \\
(1 \text { serving }=10 \text { units) }\end{array}$ & $1-2$ servings/d & 195 & $19 \cdot 7$ & 0.26 \\
\hline 11. Herbs, spices and garnish & Onion, garlic, herbs (parsley, oregano) & $\geq 1$ serving/d & 547 & 55.4 & 0.39 \\
\hline 12. Fruit & All fruit and fresh fruit-based juices ( 1 serving $=150-200 \mathrm{~g}$ ) & 3-6 servings/d & 178 & $18 \cdot 0$ & 0.32 \\
\hline 13. Vegetables & All vegetables except potatoes $(1$ serving $=150-200 \mathrm{~g}$ ) & $\geq 2$ servings/d & 790 & 80.0 & 0.39 \\
\hline 14. Olive oil & Olive oil, virgin olive oil ( 1 serving $=1$ tbsp) & $\geq 3$ servings/d & 278 & $28 \cdot 1$ & 0.24 \\
\hline 15. Cereals & $\begin{array}{l}\text { White and whole grain bread ( } 1 \text { serving }=40 \mathrm{~g}) \text {, cereals }(1 \text { serving }= \\
1 \text { plate) and derivatives }\end{array}$ & 3-6 servings/d & 291 & 29.5 & 0.17 \\
\hline \multicolumn{6}{|l|}{ Block 2: Mediterranean dietary habits } \\
\hline 16. Water or infusions & Water or infusions ( 1 serving $=1$ glass) & $\begin{array}{l}\text { 6-8 servings/d or } \\
\geq 3 \text { servings/week }\end{array}$ & 98 & $9 \cdot 9$ & 0.23 \\
\hline 17. Wine & White/red wine ( 1 serving $=1$ cup) & $1-2$ servings/d & 155 & $15 \cdot 7$ & 0.23 \\
\hline 18. Limit salt in meals & & Yes & 359 & $36 \cdot 3$ & 0.27 \\
\hline $\begin{array}{l}\text { 19. Preference for whole grain } \\
\text { products }\end{array}$ & & Yes/fibre > $25 \mathrm{~g} / \mathrm{d}$ & 502 & $50 \cdot 8$ & 0.45 \\
\hline 20. Snacks & Potatoes chips, popcorn ( 1 serving $=1$ bag or $50 \mathrm{~g}$ ) & $\leq 2$ servings/week & 973 & 98.5 & 0.10 \\
\hline 21. Limit nibbling between meals & Nibbling outside five main meals & $\overline{Y e s}$ & 683 & $69 \cdot 1$ & 0.22 \\
\hline $\begin{array}{l}\text { 22. Limit sugar in beverages } \\
\text { (including sugar-sweetened } \\
\text { beverages) }\end{array}$ & & Yes & 245 & $24 \cdot 8$ & 0.27 \\
\hline \multicolumn{6}{|c|}{ Block 3: Physical activity, rest, social habits and conviviality } \\
\hline $\begin{array}{l}\text { 23. Physical activity (>150 min/week } \\
\text { or } 30 \mathrm{~min} / \mathrm{d} \text { ) }\end{array}$ & Jogging, walking quickly, dance, aerobics, gardening & Yes & 774 & $21 \cdot 7$ & 0.20 \\
\hline 24. Siesta/nap & During weekends & Yes & 404 & 40.9 & 0.22 \\
\hline 25. Hours of sleep & During weekdays & $6-8 \mathrm{~h} / \mathrm{d}$ & 802 & $81 \cdot 2$ & 0.16 \\
\hline 26. Watching television & During weekdays & $<1 \mathrm{~h} / \mathrm{d}$ & 551 & $55 \cdot 8$ & 0.23 \\
\hline 27. Socializing with friends & During weekends & $\geq 2 \mathrm{~h} /$ weekend & 537 & 54.4 & 0.15 \\
\hline 28. Collective sports & During week & $\geq 2 \mathrm{~h} /$ week & 255 & $25 \cdot 8$ & 0.23 \\
\hline
\end{tabular}

${ }^{*} 0$ points if these criteria are not met. 
Table 2 Baseline characteristics across quintiles of the Mediterranean Lifestyle (MEDLIFE) index among a subset of participants ( $n$ 988) in the Aragon Workers' Health Study (AWHS) cohort (Zaragoza, Spain)

\begin{tabular}{|c|c|c|c|c|c|c|c|c|c|c|c|}
\hline \multirow[b]{2}{*}{ Characteristic* $^{*}$} & \multicolumn{2}{|c|}{ Q1 } & \multicolumn{2}{|c|}{ Q2 } & \multicolumn{2}{|c|}{ Q3 } & \multicolumn{2}{|c|}{ Q4 } & \multicolumn{2}{|c|}{ Q5 } & \multirow[b]{2}{*}{$P$-trend } \\
\hline & Mean & SD & Mean & SD & Mean & SD & Mean & SD & Mean & SD & \\
\hline Age (years) & $50 \cdot 8$ & 3.85 & 51.5 & 3.47 & 51.4 & 3.73 & $51 \cdot 1$ & 3.70 & $51 \cdot 2$ & 3.59 & 0.412 \\
\hline Male (\%) & \multicolumn{2}{|c|}{$97 \cdot 1$} & \multicolumn{2}{|c|}{93.6} & \multicolumn{2}{|c|}{96.8} & \multicolumn{2}{|c|}{94.3} & \multicolumn{2}{|c|}{93.8} & 0.054 \\
\hline BMI $\left(\mathrm{kg} / \mathrm{m}^{2}\right)$ & $28 \cdot 2$ & 3.80 & $27 \cdot 8$ & 3.53 & $27 \cdot 8$ & 3.52 & $27 \cdot 3$ & 3.17 & $27 \cdot 6$ & 3.67 & 0.002 \\
\hline Normal (\%) & \multirow{2}{*}{\multicolumn{2}{|c|}{$\begin{array}{l}19.0 \\
52.5\end{array}$}} & \multicolumn{2}{|c|}{$22 \cdot 7$} & \multicolumn{2}{|c|}{$20 \cdot 3$} & \multicolumn{2}{|c|}{$23 \cdot 6$} & \multicolumn{2}{|c|}{23.5} & 0.186 \\
\hline Overweight (\%) & & & & & & & \multirow{2}{*}{\multicolumn{2}{|c|}{$\begin{array}{l}58 \cdot 2 \\
18 \cdot 1\end{array}$}} & \multicolumn{2}{|c|}{$55 \cdot 8$} & 0.052 \\
\hline Obese (\%) & \multicolumn{2}{|c|}{$\begin{array}{l}52 \cdot 5 \\
28 \cdot 4\end{array}$} & \multicolumn{2}{|c|}{$26 \cdot 3$} & \multicolumn{2}{|c|}{$21 \cdot 3$} & & & & & $<0.001$ \\
\hline \multicolumn{12}{|l|}{ Smoking habits (\%) } \\
\hline Never & \multicolumn{2}{|c|}{$32 \cdot 4$} & \multicolumn{2}{|c|}{31.6} & \multicolumn{2}{|c|}{$31 \cdot 3$} & \multicolumn{2}{|c|}{$38 \cdot 0$} & \multicolumn{2}{|c|}{33.9} & 0.179 \\
\hline Former & & & & & & & & & & & 0.009 \\
\hline Current & \multicolumn{2}{|c|}{$37 \cdot 0$} & \multicolumn{2}{|c|}{$37 \cdot 3$} & \multicolumn{2}{|c|}{$35 \cdot 4$} & \multicolumn{2}{|c|}{$24 \cdot 6$} & \multicolumn{2}{|c|}{$26 \cdot 3$} & $<0.001$ \\
\hline Number of cigarettes/d & 4.95 & $8 \cdot 15$ & 4.70 & $7 \cdot 80$ & 4.47 & $10 \cdot 60$ & $2 \cdot 46$ & $5 \cdot 70$ & $2 \cdot 52$ & $5 \cdot 35$ & $<0.001$ \\
\hline Physical activity (MET-h/week) & 29.7 & $21 \cdot 0$ & 33.0 & $21 \cdot 0$ & 33.6 & $19 \cdot 7$ & 37.4 & $20 \cdot 6$ & $42 \cdot 6$ & 23.4 & $<0.001$ \\
\hline \multicolumn{12}{|l|}{ Education (\%) } \\
\hline Low & & & & & & & & & & & 0.028 \\
\hline Medium & & & & & & & & & & & 0.734 \\
\hline High & & & & & & & & & & & 0.001 \\
\hline
\end{tabular}

MET, metabolic equivalent of task.

${ }^{*}$ Continuous variables are expressed as mean and standard deviation. Categorical variables are expressed as percentages.

reported not having the habit of nibbling. Concerning rest, social habits and conviviality, $40 \cdot 9 \%$ reported that they took naps, $81.2 \%$ reported sleeping for $6-8 \mathrm{~h} / \mathrm{d}$ and $54.5 \%$ socialized with friends for $\geq 2 \mathrm{~h} /$ weekend.

Although MEDLIFE is similar to other dietary indices reported in the literature regarding food groups, there are some differences. MEDLIFE includes low-fat dairy products that were not chosen in AHEI, aMED or MEDAS, and red meat and processed meat are considered separately as two groups. Assessment of nutrients such as trans-fatty acids and $n$ - 6 PUFA are included in AHEI and aMED while in our index, as in MEDAS, these are evaluated using foods that are rich sources of these fatty acids as a proxy. Another difference is the assignment of points and cut-offs for food servings. We strictly followed the guidelines in the Spanish Mediterranean Diet Pyramid to assign the score criteria and the cut-offs ${ }^{(14)}$. Some aspects regarding serving recommendations differ from others described (see supplemental tables and Table 1). When no specific definition was available, decisions were based on a literature review of international guidelines ${ }^{(12,21-23)}$. Another difference is the final scoring system; MEDLIFE, as well as aMED and MEDAS, used dichotomous points while AHEI did not (range: 2.5-87.5). Finally, MEDLIFE includes both the assessment of food consumption directly related to the Mediterranean diet and information on behaviours associated with the Mediterranean lifestyle beyond dietary habits, to include physical activity, rest, social habits and conviviality. By definition, the Mediterranean lifestyle concept reflects the dietary and social habits patterns characteristic of the Mediterranean basin countries in the $1960 s^{(24)}$. Therefore, including additional information beyond the typical Mediterranean diet is essential to define an overall Mediterranean lifestyle.

\section{MEDLIFE intra-validity (content validity and internal consistency) and its correlation with other diet quality scores}

The mean score of the MEDLIFE index for participants in our cohort was 11.3 (SD 2.6) out of a total possible of 28. No differences by gender and age were found $(P=0.326$, and $P=0.919$, respectively). Spearman rank correlation coefficients between MEDLIFE components and the total MEDLIFE index were all significant and ranged from $0 \cdot 10$ for potatoes and snacks to 0.45 for preference for whole grain products (Table 1). Adjustment for age and energy intake did not significantly change these correlations (data not shown). The MEDLIFE index also showed good internal consistency by Cronbach's $\alpha$ coefficient (0.75).

Participants' characteristics according to quintiles of MEDLIFE index score are presented in Table 2. Those in the highest quintile compared with the lowest were more likely to have lower BMI, smoke less, be physically active and have greater education.

The associations between each MEDLIFE component and other nutrient intakes derived from the FFQ and the quintile distribution of the overall MEDLIFE index are presented in Tables 3 and 4 , respectively. The $\beta$ coefficients represent the association of the single item or nutrient with the index. Furthermore, adjusted means are presented according to the distribution of the index. The MEDLIFE index was inversely associated with the intake of sweets $(\beta=-0.29, P=0.019)$, red meat $(\beta=-0 \cdot 14$, $P<0 \cdot 001)$ and processed meat $(\beta=-0 \cdot 11, P=0 \cdot 011)$. It was also inversely associated with hours of television watched $(\beta=-0 \cdot 10, P<0 \cdot 001)$. In contrast, fish/seafood, vegetables, infusions consumption, limited added salt and sugar, preference for whole grains, physical activity and time spent on collective sports were the items that 
Table 3 Sex-, age- and energy-adjusted mean intakes of overall components of the Mediterranean Lifestyle (MEDLIFE) index according to quintile distribution of the MEDLIFE index among a subset of participants ( $n$ 988) in the Aragon Workers' Health Study (AWHS) cohort (Zaragoza, Spain)

\begin{tabular}{|c|c|c|c|c|c|c|c|c|c|c|c|c|}
\hline \multirow[b]{2}{*}{ MEDLIFE component } & \multirow[b]{2}{*}{$\beta$} & \multicolumn{2}{|r|}{ Q1 } & \multicolumn{2}{|r|}{ Q2 } & \multicolumn{2}{|r|}{ Q3 } & \multicolumn{2}{|r|}{ Q4 } & \multicolumn{2}{|r|}{ Q5 } & \multirow[b]{2}{*}{$P$ trend } \\
\hline & & Mean & $95 \% \mathrm{Cl}$ & Mean & $95 \% \mathrm{Cl}$ & Mean & $95 \% \mathrm{Cl}$ & Mean & $95 \% \mathrm{Cl}$ & Mean & $95 \% \mathrm{Cl}$ & \\
\hline Sweets (servings/week) & -0.29 & 10.88 & $10 \cdot 13,9.66$ & $10 \cdot 15$ & $9.66,10.63$ & 9.74 & $9 \cdot 25,10 \cdot 22$ & 9.32 & $8.72,9.92$ & $8 \cdot 61$ & $7.67,9.55$ & 0.019 \\
\hline Red meat (servings/week) & -0.14 & $4 \cdot 31$ & $4 \cdot 10,3.82$ & 3.95 & $3.82,4.09$ & 3.76 & $3.62,3.89$ & 3.56 & $3.39,3.72$ & 3.22 & $2.96,3.48$ & $<0.001$ \\
\hline Processed meat (servings/week) & -0.11 & 8.58 & $8.19,8.05$ & $8 \cdot 30$ & $8.05,8.55$ & 8.15 & $7.90,8.40$ & 8.00 & $7 \cdot 69,8.31$ & $7 \cdot 74$ & $7 \cdot 25,8.22$ & 0.011 \\
\hline Eggs (servings/week) & 0.01 & 3.05 & $2.82,2.93$ & 3.08 & $2.93,3.23$ & 3.09 & $2.94,3.24$ & 3.11 & $2.92,3.29$ & $3 \cdot 13$ & $2 \cdot 84,3.42$ & 0.872 \\
\hline Legumes (servings/week) & 0.05 & 1.79 & $1.72,1.88$ & 1.92 & $1.88,1.97$ & 2.00 & $1.96,2.04$ & 2.08 & $2 \cdot 02,2 \cdot 13$ & $2 \cdot 21$ & $2 \cdot 12,2 \cdot 29$ & $<0.001$ \\
\hline White meat (servings/week) & 0.05 & 1.96 & $1.81,2.00$ & $2 \cdot 10$ & $2 \cdot 00,2 \cdot 20$ & $2 \cdot 17$ & $2 \cdot 07,2 \cdot 27$ & $2 \cdot 25$ & $2 \cdot 12,2 \cdot 37$ & -0.10 & $2 \cdot 18,2 \cdot 57$ & 0.011 \\
\hline Fish/seafood (servings/week) & 0.25 & 4.39 & $4.15,4.86$ & 5.01 & $4 \cdot 86,5 \cdot 17$ & $5 \cdot 36$ & $5 \cdot 20,5 \cdot 52$ & 5.71 & $5.51,5.90$ & $6 \cdot 31$ & $6.00,6.61$ & $<0.001$ \\
\hline Potatoes (servings/week) & -0.05 & 4.13 & $3.94,3.89$ & 4.01 & $3.89,4.13$ & 3.95 & $3.83,4.06$ & 3.88 & $3.73,4.03$ & 3.77 & $3.54,4.00$ & 0.163 \\
\hline Dairy products (servings/d) & 0.04 & 0.29 & $0.22,0.34$ & 0.39 & $0.34,0.44$ & 0.45 & $0.40,0.49$ & 0.50 & $0.44,0.56$ & 0.60 & $0.51,0.69$ & $<0.001$ \\
\hline Nuts (servings/d) & 0.04 & 0.52 & $0.46,0.59$ & 0.63 & $0.59,0.67$ & 0.69 & $0.65,0.73$ & 0.75 & $0.70,0.80$ & 0.85 & $0.78,0.93$ & $<0.001$ \\
\hline Herbs (servings/d) & 0.10 & 0.82 & $0.75,1.03$ & 1.08 & $1.03,1.13$ & 1.22 & $1.17,1.27$ & 1.36 & $1.30,1.42$ & 1.61 & $1.51,1.70$ & $<0.001$ \\
\hline Fruit (servings/d) & 0.14 & 1.67 & $1.55,1.94$ & 2.01 & $1.94,2.08$ & $2 \cdot 20$ & $2 \cdot 13,2 \cdot 27$ & 2.39 & $2 \cdot 30,2.48$ & $2 \cdot 72$ & $2.58,2.86$ & $<0.001$ \\
\hline Vegetables (servings/d) & 0.22 & 2.36 & $2 \cdot 24,2 \cdot 85$ & 2.93 & $2.85,3.00$ & 3.24 & $3.16,3.32$ & 3.55 & $3.46,3.65$ & $4 \cdot 10$ & $3.95,4.24$ & $<0.001$ \\
\hline Olive oil (servings/d) & 0.11 & 2.58 & $2 \cdot 46,2.78$ & 2.86 & $2 \cdot 78,2.94$ & 3.02 & $2.94,3.10$ & 3.18 & $3.08,3.27$ & 3.45 & $3.29,3.60$ & $<0.001$ \\
\hline Cereals (servings/d) & 0.02 & 3.27 & $3.14,3.23$ & 3.31 & $3.23,3.39$ & 3.34 & $3.25,3.42$ & 3.36 & $3.26,3.46$ & 3.40 & $3.24,3.56$ & 0.348 \\
\hline Tea (servings/week) & 0.23 & 0.00 & $-0.28,0.41$ & 0.59 & $0.41,0.77$ & 0.92 & $0.74,1 \cdot 10$ & 1.25 & $1.03,1.47$ & 1.82 & $1 \cdot 47,2 \cdot 17$ & $<0.001$ \\
\hline Limit saltt* & 0.24 & $20 \cdot 80$ & $15 \cdot 10,26 \cdot 80$ & $32 \cdot 40$ & $26 \cdot 80,38.00$ & 37.90 & $30 \cdot 20,45 \cdot 70$ & 43.80 & $37.40,50 \cdot 10$ & $65 \cdot 20$ & $56.80,73.50$ & $<0.001$ \\
\hline Preference whole grains* & 0.46 & $25 \cdot 20$ & $20 \cdot 40,41 \cdot 70$ & $46 \cdot 50$ & $41 \cdot 70,51 \cdot 30$ & 57.80 & $51 \cdot 20,64.50$ & $67 \cdot 10$ & $51.20,64.50$ & $67 \cdot 10$ & $61.60,72.60$ & $<0.001$ \\
\hline Wine (servings/d) & 0.02 & 0.91 & $0.78,0.88$ & 0.96 & $0.88,1.04$ & 0.99 & $0.91,1.07$ & 1.01 & $0.91,1.11$ & 1.06 & $0.91,1.22$ & 0.507 \\
\hline Snacks (servings/week) & -0.01 & 0.14 & $0.11,0.10$ & 0.13 & $0.10,0.15$ & 0.12 & $0.09,0.14$ & 0.11 & $0.08,0.14$ & 0.09 & $0.05,0.14$ & 0.126 \\
\hline Limit nibbling* & 0.18 & $42 \cdot 30$ & $36 \cdot 80,27 \cdot 40$ & 32.80 & $27 \cdot 40,38 \cdot 20$ & $29 \cdot 10$ & $21 \cdot 50,36 \cdot 70$ & $24 \cdot 10$ & $17 \cdot 80,30 \cdot 30$ & $15 \cdot 10$ & $6 \cdot 90,23 \cdot 20$ & $<0.001$ \\
\hline Limit sugar* & 0.34 & 88.40 & $83.50,77.90$ & 82.7 & $77.90,87.40$ & 75.50 & $68 \cdot 80,82 \cdot 20$ & 64.60 & $59 \cdot 20,70 \cdot 00$ & $46 \cdot 30$ & $39 \cdot 10,53 \cdot 40$ & $<0.001$ \\
\hline Physical activity* & 0.26 & $65 \cdot 50$ & $60.60,70.00$ & 74.80 & $70.00,79.60$ & $85 \cdot 30$ & $78.50,92 \cdot 00$ & $86 \cdot 40$ & $80.90,92.00$ & $93 \cdot 10$ & $85.80,100.00$ & $<0.001$ \\
\hline $\mathrm{Nap}^{*}$ & $0 \cdot 17$ & $29 \cdot 70$ & $23.80,28.90$ & 34.7 & $28.90,40.50$ & $45 \cdot 10$ & $37.00,53.30$ & 51.60 & $45.00,58.30$ & $55 \cdot 10$ & $46 \cdot 40,63 \cdot 80$ & 0.001 \\
\hline Hours of sleep/d & 0.03 & 6.08 & $5.98,6 \cdot 10$ & $6 \cdot 17$ & $6 \cdot 10,6 \cdot 23$ & $6 \cdot 21$ & $6 \cdot 15,6.28$ & $6 \cdot 26$ & $6 \cdot 18,6 \cdot 34$ & 6.34 & $6.21,6.47$ & 0.001 \\
\hline Television hours/d & -0.10 & 1.85 & $1.75,1.52$ & 1.59 & $1.52,1.65$ & 1.44 & $1.38,1.50$ & 1.29 & $1.21,1.37$ & 1.04 & $0.92,1.15$ & $<0.001$ \\
\hline Socialize (h/weekend) & 0.14 & 1.51 & $1.31,1.72$ & 1.85 & $1.72,1.98$ & 2.04 & $1.91,2.17$ & 2.23 & $2.07,2.39$ & 2.56 & $2 \cdot 31,2 \cdot 81$ & $<0.001$ \\
\hline Collective sports (h/week) & 0.34 & 0.41 & $0.12,1.08$ & 2.00 & $1.08,1.45$ & 1.74 & $1.56,1.93$ & $2 \cdot 22$ & $1.99,2.45$ & 3.05 & $2.69,3.40$ & $<0.001$ \\
\hline
\end{tabular}

${ }^{*}$ Categorical variables are presented as the percentage of people who reach 1 point and $95 \%$ confidence interval. 
contributed most to the MEDLIFE index, with $\beta$ coefficients higher than $0 \cdot 20$. Herbs, spices and other garnish, fruit, olive oil, limited nibbling or snacking, napping habits and socialize hours showed moderate but significant direct associations with the MEDLIFE index ( $\beta$ range: $0.10-0.20 ; P<0.001$ ). A smaller but significant contribution to MEDLIFE was found for legumes, white meat, dairy products, nuts and hours of sleep $(P<0.05)$. All of these associations are also consistent according to quintiles of distribution $(P$ trend $<0 \cdot 05)$. No statistically differences were found for eggs, potatoes, cereals, wine and snack consumption.

As for nutrient consumption, percentage of energy from MUFA and PUFA, specifically $n$-3 (different from fish), was associated with increasing MEDLIFE quintiles. Similar results were observed for vitamin $\mathrm{C}, \mathrm{Ca}$ and $\mathrm{Fe}(P$ trend $<0.001$ for all). However, a significant and inverse association was found for percentage of energy from SFA and trans-fatty acids, sugar and glycaemic load $(P$ trend $<0.001$ for all; Table 4). These results are consistent with those reported in other studies comparing dietary indices created from FFQ and nutrient adequacy (content validity and internal consistency) ${ }^{(7,25-27)}$.

Concerning the other diet quality scores assessed, the mean values were as follows: $\operatorname{aMED}=4.0$ (sD 1.8), AHEI $=49.5(\mathrm{sD}$ 9.0) and MEDAS $=6.5$ (SD 1.7). Similar mean values were found regarding aMED and AHEI in the NHS and HPFS ${ }^{(1,25)}$. MEDAS scoring was approximately 2 points lower in our population compared with other Spanish populations ${ }^{(28,29)}$. However, our population is younger and older populations seem to better preserve the Mediterranean habits.

With regard to the association between these diet quality indices and MEDLIFE, the MEDLIFE index was significantly associated with AHEI, aMED and MEDAS ( $\rho$ range: $0.44-$ 0.53; $P<0.001$; Table 5). MEDLIFE correlated the most with MEDAS $(\rho=0.53)$ and AHEI $(\rho=0.52 ; P<0.001$ for both $)$ although the highest correlation was seen between AHEI and aMED because many of the items in each index are based on similar dietary recommendations; this is comparable to the results reported by Fung et $a l^{(1)}$. Analysing MEDLIFE by blocks, the first two (food consumption and Mediterranean dietary habits) correlated strongly with MEDAS $(\rho=0.557$ and 0.568 , respectively; $P<0.001$ for both) probably because MEDAS also includes two questions about food intake habits and both have been developed based on the Mediterranean diet. In addition, to analyse the strength of correlation between indices, we also evaluated the agreement between indices. The results were along the same lines as the correlations $(P<0 \cdot 001)$, giving evidence that the MEDLIFE index successfully captures overall quality diet and the Mediterranean diet.

\section{Strengths and limitations}

The current paper presents the description and development of an index to measure adherence to a Mediterranean lifestyle. Compared with the other indices described, it is 
Table 5 Spearman's correlation coefficients among diet quality scores from the FFQ completed by a subset of participants ( $n$ 988) in the Aragon Workers' Health Study (AWHS) cohort (Zaragoza, Spain)

\begin{tabular}{|c|c|c|c|c|c|c|}
\hline & aMED & AHEI & MEDAS & MEDLIFE & MEDLIFE-FC & MEDLIFE-FC + DH \\
\hline aMED & 1.00 & & & & & \\
\hline $\mathrm{AHEI}$ & 0.62 & 1.00 & & & & \\
\hline MEDAS & 0.50 & 0.56 & 1.00 & & & \\
\hline MEDLIFE & 0.44 & 0.52 & 0.53 & 1.00 & & \\
\hline MEDLIFE-FC & 0.38 & 0.48 & 0.56 & 0.76 & 1.00 & \\
\hline MEDLIFE-FC + DH & 0.47 & 0.54 & 0.57 & 0.89 & 0.86 & 1.00 \\
\hline
\end{tabular}

aMED, Alternate Mediterranean Diet Score; AHEI, Alternate Healthy Eating Index; MEDAS, Mediterranean Diet Adherence Screener; MEDLIFE, Mediterranean Lifestyle index; MEDLIFE-FC, MEDLIFE food consumption; MEDLIFE-FC + DH, MEDLIFE food consumption + dietary habits.

All $P$ values are $<0.001$.

the first overall quality index that aims to measure other variables beyond food consumption that are part of the Mediterranean lifestyle definition (physical activity, adequate rest, sociability and conviviality). Beneficial effects of the Mediterranean diet have been widely recognized internationally by the scientific community ${ }^{(30)}$. Therefore, the development of our index aims to be valid not only in Spain but also elsewhere. Its items can be easily defined by the FFQ used in epidemiological studies that can facilitate its internationality.

We have to note that because we assessed diet using a semi-quantitative FFQ, we have to assume some of the disadvantages related to this tool (by its nature, some misclassification can occur and it is less precise than other tools). However, the previous validation study of this $\mathrm{FFQ}^{(17)}$ and other scientific literature supports that FFQ rank usual intakes well ${ }^{(31)}$.

In addition, the fact that the MEDLIFE index was developed in a population including mostly men and belonging to a specific population (General Motors Spain automobile assembly plant) could be regarded as a limitation, but it should not affect the development of the index. Women tend to be more accurate in reporting dietary consumption and other studies have found that women seem to have better scores in dietary indices than men ${ }^{(9,32)}$. During the replication on an independent population, possible gender-based biases as well as other possible interactions will be evaluated. A further step conducting an external validation will help us to elucidate some of these issues.

Another limitation is that the scale of scoring this index is categorical. One of the major goals of this instrument is to use it as a short screener in epidemiological and clinical studies to assess potential health benefits associated with the Mediterranean lifestyle, so we considered that people in clinical practice could obtain easily a Mediterranean lifestyle score if we used a 0 or 1 point scoring system. However, this categorization may limit the range of possible scores and then have some limitations. One of the limitations might be that, when evaluating changes in the score over time, differences among groups are more difficult to detect. Therefore, we do not discard that a future scoring system considering both continuous and categorical scales may be developed to assess associations with health outcomes and evaluate changes over time in epidemiological studies. A continuous scale has the advantage of increasing the sensitivity and therefore the ability to detect changes over time. In addition, it does not assume a linear relationship when the aim is to study associations with health outcomes. Finally, as in previously developed indices, the development always implies some arbitrary decisions regarding those items that are not specifically named in the food pyramid as well as in the assignment of cut-off points that need to be considered when using the instrument.

\section{Conclusions}

MEDLIFE correlates well with other previously validated diet quality indices, validating its use. Previous indices analysed have been associated with favourable intermediate and final cardiovascular risk phenotypes and overall health effects ${ }^{(25,26,28,30,33)}$. Hence, considering that MEDLIFE implies a more comprehensive assessment of lifestyle, we expect it will help to refine the associations between the Mediterranean diet (lifestyle) and chronic disease. MEDLIFE is a short measuring instrument that could be used in future epidemiological and clinical studies as a valid instrument to measure adherence to the Mediterranean lifestyle.

\section{Acknowledgements}

Financial support: This study was funded by the Spanish National Research Fund R+D, project PI11/00403, 2012-2015 (Polymorphism APOA2-265T > C in relation to dietary patterns and cardiovascular risk factors). The Spanish National Research Fund $\mathrm{R}+\mathrm{D}$ had no role in the design, analysis or writing of this article. Conflict of interest: None. Authorship: M.S.-P. conceived and designed the MEDLIFE index, performed data management, statistical analyses and interpretation, and drafted the manuscript. B.M.-F. assisted with data collection, administrative and technical support and drafting of the manuscript. J.M.O., M.L. and J.A.C. conceived the AWHS (obtaining funding) and supervised 
the manuscript. J.L.P. conceived and designed the study, obtained funding and helped to draft the manuscript: Etbics of human subject participation: The AWHS was approved by the Central Institutional Review Board of Aragón (CEICA), Spain.

\section{Supplementary material}

To view supplementary material for this article, please visit http://dx.doi.org/10.1017/S1368980014001360

\section{References}

1. Fung TT, McCullough ML, Newby PK et al. (2005) Dietquality scores and plasma concentrations of markers of inflammation and endothelial dysfunction. Am J Clin Nutr 82, 163-173.

2. Estruch R, Martinez-Gonzalez MA, Corella D et al. (2006) Effects of a Mediterranean-style diet on cardiovascular risk factors - a randomized trial. Ann Intern Med 145, 1-11.

3. McCullough ML, Feskanich D, Stampfer MJ et al. (2002) Diet quality and major chronic disease risk in men and women: moving toward improved dietary guidance. $A m J$ Clin Nutr 76, 1261-1271.

4. Estruch R, Ros E, Salas-Salvado J et al. (2013) Primary prevention of cardiovascular disease with a Mediterranean diet. New Engl J Med 368, 1279-1290.

5. Kennedy ET, Ohls J, Carlson S et al. (1995) The Healthy Eating Index - design and applications. J Am Diet Assoc 95, 1103-1108.

6. Trichopoulou A, Costacou T, Bamia C et al. (2003) Adherence to a Mediterranean diet and survival in a Greek population. N Engl J Med 348, 2599-2608.

7. Schröder H, Fitó M, Estruch R et al. (2011) A short screener is valid for assessing Mediterranean diet adherence among older Spanish men and women. J Nutr 141, 1140-1145.

8. Chiuve SE, Fung TT, Rexrode KM et al. (2011) Adherence to a low-risk, healthy lifestyle and risk of sudden cardiac death among women. JAMA 306, 62-69.

9. Bhupathiraju SN, Lichtenstein AH, Dawson-Hughes B et al. (2011) Adherence index based on the AHA 2006 diet and lifestyle recommendations is associated with select cardiovascular disease risk factors in older Puerto Ricans. J Nutr 141, 460-469.

10. Behrens G, Fischer B, Kohler S et al. (2013) Healthy lifestyle behaviors and decreased risk of mortality in a large prospective study of US women and men. Eur J Epidemiol $\mathbf{2 8}$ 361-372.

11. Laugero KD, Falcon LM \& Tucker KL (2011) Relationship between perceived stress and dietary and activity patterns in older adults participating in the Boston Puerto Rican Health Study. Appetite 56, 194-204.

12. Cappuccio FP, D'Elia L, Strazzullo P et al. (2010) Sleep duration and all-cause mortality: a systematic review and meta-analysis of prospective studies. Sleep 33, 585-592.

13. Burazeri G, Gofin J \& Kark JD (2003) Siesta and mortality in a Mediterranean population: a community study in Jerusalem. Sleep 26, 578-584.

14. Bach-Faig A, Berry EM, Lairon D et al. (2011) Mediterranean diet pyramid today. Science and cultural updates. Public Health Nutr 14, 2274-2284.

15. Fundación Dieta Mediterránea (2010) Mediterranean Diet Pyramid: a lifestyle for today. http://dietamediterranea.com/ dietamed/piramide_INGLES.pdf (accessed July 2014).
16. Casasnovas JA, Alcaide V, Civeira F et al. (2012) Aragon workers' health study - design and cohort description. BMC Cardiovasc Disord 12, 45.

17. de la Fuente-Arrillaga C, Ruiz ZV, Bes-Rastrollo M et al. (2010) Reproducibility of an FFQ validated in Spain. Public Health Nutr 13, 1364-1372.

18. Martinez-Gonzalez MA, Lopez-Fontana C, Varo JJ et al. (2005) Validation of the Spanish version of the physical activity questionnaire used in the Nurses' Health Study and the Health Professionals' Follow-up Study. Public Health Nutr 8, 920-927.

19. Chasan-Taber S, Rimm EB, Stampfer MJ et al. (1996) Reproducibility and validity of a self-administered physical activity questionnaire for male health professionals. Epidemiology 7, 81-86.

20. Wolf AM, Hunter DJ, Colditz GA et al. (1994) Reproducibility and validity of a self-administered physical activity questionnaire. Int J Epidemiol 23, 991-999.

21. Haskell WL, Lee IM, Pate RR et al. (2007) Physical activity and public health: updated recommendation for adults from the American College of Sports Medicine and the American Heart Association. Circulation 116, 1081-1093.

22. Sofi F, Cesari F, Abbate R et al. (2008) Adherence to Mediterranean diet and health status: meta-analysis. BMJ 337, a1344.

23. Burazeri G, Gofin J \& Kark JD (2003) Over 8 hours of sleep - marker of increased mortality in Mediterranean population: follow-up population study. Croat Med J $\mathbf{4 4}$, 193-198.

24. Keys A, Menotti A, Karvonen MJ et al. (1986) The diet and 15-year death rate in the seven countries study. Am J Epidemiol 124, 903-915.

25. de Koning L, Chiuve SE, Fung TT et al. (2011) Diet-quality scores and the risk of type 2 diabetes in men. Diabetes Care 34, 1150-1156.

26. Fung TT, Rexrode KM, Mantzoros CS et al. (2009) Mediterranean diet and incidence of and mortality from coronary heart disease and stroke in women. Circulation 119, 1093-1100.

27. Heidemann C, Hoffmann K, Spranger J et al. (2005) A dietary pattern protective against type 2 diabetes in the European Prospective Investigation into Cancer and Nutrition (EPIC) - Potsdam Study cohort. Diabetologia $\mathbf{4 8}$, $1126-1134$.

28. Martinez-Gonzalez MA, Garcia-Arellano A, Toledo E et al. (2012) A 14-item Mediterranean diet assessment tool and obesity indexes among high-risk subjects: the PREDIMED trial. PLOS One 7, e43134.

29. Jurado D, Burgos-Garrido E, Diaz FJ et al. (2012) Adherence to the Mediterranean dietary pattern and personality in patients attending a primary health center. J Acad Nutr Diet 112, $887-891$.

30. Sotos-Prieto M, Angeles Zulet M \& Corella D (2010) Scientific evidence of the Mediterranean diet effects in determining intermediate and final cardiovascular disease phenotypes. Med Clin (Barc) 134, 22-29.

31. Willett W (editor) 1998) Food frequency methods. In Nutritional Epidemiology, 2nd ed., pp 74-94. New York: Oxford University Press.

32. Mattei J, Bhupathiraju S \& Tucker KL (2013) Higher adherence to a diet score based on American Heart Association recommendations is associated with lower odds of allostatic load and metabolic syndrome in Puerto Rican adults. J Nutr 143, 1753-1759.

33. Akbaraly TN, Sabia S, Shipley MJ et al. (2013) Adherence to healthy dietary guidelines and future depressive symptoms: evidence for sex differentials in the Whitehall II study. Am J Clin Nutr 97, 419-427. 